\title{
Conflict of interest in nutrition research: an editorial perspective
}

\author{
M. J. Soares $\mathbb{1}^{1} \cdot$ M. J. Müller ${ }^{2}$ H. Boeing ${ }^{3} \cdot$ C. Maffeis $\mathbb{1}^{4} \cdot$ A. Misra $\mathbb{D}^{5} \cdot$ G. Muscogiuri ${ }^{6} \cdot$ S. Muthayya ${ }^{7}$. \\ P. Newsholme ${ }^{8} \cdot$ T. Wolever ${ }^{9} \cdot$ S. Zhu ${ }^{10}$
}

Received: 16 July 2019 / Accepted: 19 July 2019

C) Springer Nature Limited 2019

Present day research and academic institutes gauge individual research success, to a large extent, on the ability of each scientist to consistently bring in research dollars. This, in turn, depends on the scientist's publication record and the success of his or her research; i.e., that the scientist's experiments have a positive, statistically significant result which supports the scientist's original hypothesis. Thus, all scientists have an academic conflict of interest-in that the impact of their research, their ability to attract research funding, and perhaps to keep their jobs, depends upon their having research success. This type of conflict of interest (COI) is generally ignored by the scientific community, but it is real and it can be very strong. Most discussion about COI focuses on funding received from the industry. Depending on the nation in question, research funding comes from public and industry-based inputs coupled with a few international funding agencies. The food industry has steadily increased its investment in externally targeted research, and academics are drawn to such funds for a number of reasons. They are less arduous to apply for, and often, offer a greater chance of being funded. Successful completion of such projects usually lead to long-term collaborations that ensure continued research income. It is a

M. J. Soares

m.soares@curtin.edu.au

$\triangle$ M. J. Müller

mmueller@nutrfoodsc.uni-kiel.de

1 School of Public Health, Faculty of Health Sciences, Curtin University, Perth, WA, Australia

2 Institute of Human Nutrition \& Food science, Christian Albrechts Universität, Kiel, Germany

3 German Institute of Human Nutrition Potsdam-Rehbruecke Arthur Scheunert-Allee, Nuthetal, Germany

4 Department of Surgery, Dentistry, Paediatrics, and Gynaecology, University of Verona, Verona, Italy fact that industry-sponsored research has been with us from the beginning of modern science. Otherwise, the development of newer drugs, medical technologies for the detection and treatment of disease, and the like, would not have been possible.

All industries work toward their own profit. The food industry is no exception [1,2], and has been implicated in plans to subvert the nutrition/public health agenda. Industry sponsorship has shown a clear bias toward outcomes that benefit their businesses [3-5]. For example, in a systematic review (SR) of systematic reviews on the link between sugar-sweetened beverages (SSB) and weight gain, the authors concluded that industry sponsorship was five times more likely not to show an association [4]. The implication is that the authors were "paid" to come to a conclusion which favored industry. However, it seems more likely, given the wide range of opinions about dietary sugars, that industry choose to support those scientists whose preexisting opinions on the matter were more favorable to industry.

An alternative view could be that studies with no COI (i.e., not supported by industry) were more likely to have been conducted by anti-food industry scientists and, thus,

5 Fortis CDOC Hospital for Diabetes and Allied Specialities, New Delhi, India

6 Endocrinology Unit, Department of Clinical Surgery and Medicine University Federico II of Naples, Naples, Italy

7 The Sax Institute, Sydney School of Public Health, University of Sydney, Sydney, NSW, Australia

8 School of Pharmacy and Biomedical Sciences, Faculty of Health Sciences, Curtin University, Perth, WA, Australia

9 Department of Nutritional Science and Medicine, Faculty of Medicine, University of Toronto, Toronto, Canada

10 Chronic Disease Research Institute, Department of Nutrition and Food Hygiene, School of Public Health, and Women's Hospital, School of Medicine, Zhejiang University, Hangzhou, China 
show a positive association. This is a matter of interpretation, and hence a limitation of that study. As questioned by the editor of the journal that published that paper, "..could non-industry sponsored authors have a pre-existing prejudice favouring an association between SSB and weight gain?" Clearly, there is a need for self-reflection by the scientist prior to embarking on industry-based research, but also of the scientist seeking to prove their favored hypothesis.

There has been earnest discussion about COI in nutrition research [6,7], and editorial boards are faced with this question on a daily basis. So how do we, as editors, progress the outcomes of research funded by the food and related industries, co-written with their scientists, or solely from such organizations? The answers to these questions are not straight forward [6-8], and need consensus across the discipline. Most editors when presented with a paper, whether with or without a COI, will treat the methods, raw data collected, and analysis, as honest. As editors if we start with the presumption that everyone is out to "cheat" their way into a paper, then our job becomes impossible! Clearly, any declaration of COI will alert the editor and reviewers, and understandably, bring all aspects of the paper under increased scrutiny. The collection and analysis of the data, its interpretation, and hence its conclusions are open to interrogation. The review process of the journal will uncover any shortfalls in these areas, and seek further clarifications of the authors. As editors, we have to allow for differing views on the interpretation of the results, and more so, when refereeing a contentious topic. This is a mark of respect for the scientist, and an acknowledgement that we do not "know it all". Differences in interpretation are also good for the science, since it sets up the opportunity for debate within the nutrition community. A healthy discussion invariably informs the next approach to the problem. Therefore, in our opinion, a paper with a COI should be published if it has been internally and externally peer reviewed, and meets the journal's standards.

The food industry is part of our everyday life and scientific community. They have research questions that are mechanistic in nature, as well as specifically related to the potential health benefits of their new products. To avoid bias, such questions are best answered by scientists who are independent of the industry, and the key issue confronting these researchers is finding a pragmatic way to separate scientific from commercial interests. As a guideline, one may follow the slightly modified words of Jukola [9] who wrote "The prevalence of commercial funding becomes problematic if it leads to a situation where the body of available evidence that is used for making health policy decisions (or understanding the science per se), does not reflect the shared sense of what are the epistemic and nonepistemic goals of the inquiry".
We recently convened an editorial meeting where this and related matters were discussed, and the directions set out by Mozaffarian [6] for good industry-academic linkages were central to our dialog. The following viewpoint is aimed at finding a pathway that allows greater transparency in all future EJCN publications.

So how do we plan to handle the papers that stem from industry-based collaborations? Let us assume we receive a paper with a clearly declared COI that has an interesting hypothesis, addresses an area of current debate, or hopes to confirm the clinical benefits of a nutritional product. Further, that the overall ethics of human research, writing, and methods pass our initial quality checks. We will employ the following categorization:

Category 1: Studies financed by industry (in part or total) but with a clear declaration that the industry was not involved in the study hypothesis/design, execution, analysis, or interpretation.

Category 2: Studies sponsored by industry (in part or total), with a clear declaration that industry was involved in the study hypothesis/design, execution, analysis, or interpretation, and the industry involvement in each aspect is clearly outlined.

Category 3: Studies funded and conducted by industry, with no external partners.

All submitted papers in categories 1 and 2 will need to address the following four points (1-3 from Mozafarrian [6]) in the cover letter to editor, or EJCN will return the submission for completion.

1. Statement that industry funding was transparent, acknowledged, and appropriately recognized throughout all stages of design, implementation, and reporting.

2. Evidence presented that project design, implementation, analysis, and interpretation had been performed with efforts to maximize academic independence in each of these areas.

3. Confirmation of full academic independence to report and publish all the findings.

4. Statement that all raw data will be uploaded to a publically accessible repository, or be made available to interested scientists if requested; understanding that there could be reasonable caveats for such requests. Any restrictions on material availability or other relevant information to be divulged in the paper's methods section, and should include details of how materials and information may be obtained.

Once systematically assessed and accepted for publication, category 1 papers will appear as standard when published. In contrast, categories 2 and 3 when published will appear under the subject category "Industry Research"; 
irrespective of the article type. While this decision will be made by the handling editor, this new subject category may be selected by the corresponding authors of category 2 and 3 papers, at the time of submission. The introduction of this new subject category will signal papers with a strong but declared COI. The reader can then make a judgment on the veracity of the findings, and the overall message of that paper.

\section{Compliance with ethical standards}

Conflict of interest Authors MJS, MJM, HB, CM, SM, GM, PN, and SZ have no conflicts of interest to declare. AM has received grants and honoraria from Almond Board of California, Herbalife India and Azzkaa pharmaceuticals. TW is a part owner and receives payment as the President and Medical Director of Glycemic Index Laboratories, Inc., (GI Labs, a contract research organization) and Glycemic Index Testing, Inc., (GI Testing, which supplies services to GI Labs) Toronto, Canada. He has authored or co-authored several books on the glycemic index for which has received royalties from Phillipa Sandall Publishing Services and CABI Publishers. He has received research support, consultant fees or honoraria from or served on the scientific advisory board for Canadian Institutes of Health Research, Canadian Diabetes Association, Dairy Farmers of Canada, Agriculture AgriFood Canada, Public Health Agency of Canada, GI Labs, GI Testing, Abbott, Proctor and Gamble, Mars Foods, McCain Foods, Bunge, Temasek Polytechnic Singapore, Northwestern University, Royal Society of London, Glycemic Index Symbol program, CreaNutrition AG, McMaster University, University of Manitoba, University of Alberta, Canadian Society for Nutritional Sciences, National Sports and Conditioning Association, Faculty of Public Health and Nutrition - Autonomous University of Nuevo Leon, Diabetes and Nutrition Study Group of the European Association for the Study of Diabetes (EASD). His wife is part owner of Glycemic Index Laboratories, Inc., and Glycemic Index Testing, Inc., and receives payment as chief financial officer of both corporations.
Publisher's note: Springer Nature remains neutral with regard to jurisdictional claims in published maps and institutional affiliations.

\section{References}

1. Nestle M. Coca-Cola says its drinks don't cause obesity. Science says otherwise. https://www.theguardian.com/commentisfree/ 2015/aug/11/coca-cola-obesity-health-studies.

2. Soares MJ, Muller MJ. Thirty years of EJCN: a time for reflection. Eur J Clin Nutr. 2018;72:1195-7.

3. Lesser LI, Ebbeling CB, Goozner M, Wypij D, Ludwig DS. Relationship between funding source and conclusion among nutrition-related scientific articles. PLoS Med. 2007;4:e5. https:// doi.org/10.1371/journal.pmed.0040005.

4. Bes-Rastrollo M, Schulze MB, Ruiz-Canela M, Martinez-Gonzalez MA. Financial conflicts of interest and reporting bias regarding the association between sugar-sweetened beverages and weight gain: a systematic review of systematic reviews. PLoS Med. 2013;10: e1001578. https://doi.org/10.1371/journal.pmed.1001578.

5. Chartres N, Fabbri A, Bero LA. Association of industry sponsorship with outcomes of nutrition studies: a systematic review and meta-analysis. JAMA Intern Med. 2016;176:1769-77.

6. Mozaffarian D. Conflict of interest and the role of the food industry in nutrition research. JAMA. 2017;317:1755-6.

7. Ioannidis JPA, Trepanowski JF. Disclosures in nutrition research: why it is different. JAMA. 2018:319:547-8.

8. Cullerton K, Adams J, Forouhi N, Francis O, White M. What principles should guide interactions between population health researchers and the food industry? Systematic scoping review of peer-reviewed and grey literature. Obes Rev. 2019;1-12. https:// doi.org/10.1111/obr.12851.

9. Jukola S. Commercial interests, agenda setting, and the epistemic trustworthiness of nutrition science. Synthese. 2019. https://doi.org/ 10.1007/s11229-019-02228-3. 